\title{
Long-term selection experiment with Afrikaner cattle 3. Selection applied and response in calf growth traits
}

\author{
L.M. Beffa ${ }^{1,2,3}$, J.B. van Wyk ${ }^{1 \#}$ and G.J. Erasmus ${ }^{1}$ \\ ${ }^{1}$ University of the Free State, P.O. Box 339, Bloemfontein 9300, South Africa \\ ${ }^{2}$ Matopos Research Station, P. Bag K5137, Bulawayo, Zimbabwe
}

\begin{abstract}
A selection and line $\mathrm{x}$ environment interaction study with grade Afrikaner cattle was established in 1956 at Matopos Research Station, Zimbabwe. Two selection lines of 100 cows each were reared in different management environments. The non-supplemented (NS) line relied on the range throughout the year and was mated to calve with the onset of the rains (December to February). The supplemented (S) line was offered protein-rich supplements during the dry season and mated to calve prior to the onset of the rains (October to December). In 1976, after approximately two generations of selection, lines were sub-divided into 75 cows each, where one sub-line remained within each environment as a control; the remaining sub-lines were interchanged between environments. Bulls were selected on weaning weight within control lines, while replacement heifers were selected on weight at mating within sub-line. Data recorded over approximately six generations of selection (40 years) were analyzed. The average age of sires and dams at the time of birth of their progeny was 5.9 and 7.5 years respectively in the pre-crossover phase and was reduced to 4.4 and 6.5 years respectively in the post-crossover phase. The rate of inbreeding across lines and environments was 1.2\%/generation. The cumulative selection differential trends for both the $\mathrm{S}$ and NS lines for adjusted weaning weight plotted against generation number were very low, relatively linear and greater for the $S$ line (0.10 s.d./year) compared with the NS line (0.08 s.d./year). Direct and correlated responses were uniformly low, approximating $1 \%$ of the trait mean per generation, and indicating that considerable attention was given to secondary characters. These results concur with general findings of effective direct and correlated responses of weight traits to individual selection.
\end{abstract}

Keywords: Sanga, sub-tropics, correlated response

\# Corresponding author. E-mail: vanwykjb.sci@ufs.ac.za

${ }^{3}$ Current address. Livestock Identification Trust, P.O. Box BE 209, Belvedere, Harare, Zimbabwe

\section{Introduction}

Selection experiments in beef cattle have been mainly concerned with improvements in growth traits, with published reports of 1.8 to 6.3 generations of selection (Mrode, 1988b; Baker et al., 1991; Koch et al., 1994; Parnell et al., 1997; Razook et al., 1998; Mercadante et al., 2003, Koch et al., 2004; Pereira et al., 2008). However, Mrode (1988a) noted that many earlier experiments suffered from inadequate designs with respect to population size and levels of inbreeding. In their review, Baker \& Morris (1984) reported that selection responses for weights have been closer to half of the expected response and approximated $1 \% / g e n e r a t i o n$. Two primary reasons for this have been a lower realized heritability and that the applied selection differential has been less than expected due to natural selection and attention paid to secondary traits. Realized heritability estimates have been widely used to determine the effect of selection, while being cognizant of the wide variations and large errors associated with these estimates mostly attributed to chance effects of random drift (Falconer, 1977). Even in dairy cattle where focus is on a single trait - milk yield actual response has been much lower than predicted due to lower applied selection intensities and attention being given to non-production traits (Van Vleck, 1977).

Numerous studies (cited above) have reported positive correlated responses of weights at different stages of growth, as expected, given the positive genetic correlation between these traits. In one exception, selection for weight for age under conditions of moderate to high stress, birth weight decreased while weight at all other ages increased (Frisch, 1981), leading the authors to conclude that selection for growth in a stressful environment did not improve inherent growth potential, but resulted in increased resistance to 
environmental stress. The objective of this study was to determine direct and correlated selection pressure applied and response in calf weights and weight gains over a 40-year period with Afrikaner cattle.

\section{Materials and Methods}

The experimental protocol, calf growth traits, development of fixed effect models and parameter estimates have been reported in companion papers (Beffa et al., 2009a; b). Briefly, the experiment was carried out in the sub-tropical environment of Matopos Research Station, Zimbabwe, which is subject to wide fluctuations in the quantity and distribution of rainfall within and across season. Mean annual rainfall is $566 \mathrm{~mm}$ and occurs between November and March followed by a long dry season. Two lines of 100 grade Afrikaner cows each were established in 1956 and subjected to different nutritional and management regimes, hereafter termed environments. The supplemented (S) line cows were offered supplements during the dry season and mated to calve early (October to December) relative to the expected onset of the rains. The non-supplemented (NS) line cows were mated to calve two months later than the S line. A fixed mating season of 90 days and four single-sired herds of 25 cows each were used within each line. Selection for weight within line, to establish lines adapted to their respective environments, was based on weight at weaning for bulls and weight prior to mating (three years) for replacement heifers. In 1976 the number of breeding females in each line was increased to 150 and two equal sub-lines were created. One sub-line remained within each environment as a control; the remaining sub-lines were interchanged between environments. Bulls were selected within the control sub-lines and were used within line across environments. Cows were mated in five single-sire herds of 15 cows each. Four bulls were replaced each year and one was retained as a repeat sire. The data analyzed in this study were collected over 40 years (1958 to 1997).

Weights at birth (BW), weaning (WW), 12 (W12) and 18 months (W18), and post-weaning gain (PWG) (between 12 and 18 months) were analyzed. In order to account for all interactions with year of birth, a concatenation of line-year-environment classification was employed. For all the traits, only two classes of sex were considered. Pre-weaning, these were intact male versus female and post-weaning, these were steer versus heifer. Similarly, in order to account for the interaction as well as confounding of heifer with previous lactation status (PLS), a class model concatenating three classes for PLS (three year old heifers; cows not suckling in the previous season; and cows that had suckled a calf at least up to and until the calf had attained 90 days of age) with five age of dam classes (3, 4, 5 to 7, 8 to 10 and $>10$ years of age) was employed. The effects of birth date were accounted for by its inclusion as a cross-classified covariate regressed from the year-environment subclass means.

Mixed model procedures (ASREML: Gilmour et al., 2002) allowing for the inclusion of the interaction sire $\mathrm{x}$ year, direct and maternal genetic random effects, as well as their correlation, and permanent environmental random effects due to repeated measures on the dam, were used to derive best linear unbiased predictors (BLUP) of animals' estimated breeding values (EBV). The random components in 'best-fit' models, their derivation being described in detail in the companion paper (Beffa et al., 2009b), used to derive EBV's for each trait are summarized in Table 1 . The generation number of an individual $\left(G_{i}\right)$ was calculated using the formula of Brinks et al. (1961): $G_{i}=1+\left(G_{s}+G_{d}\right) / 2$ where $G_{s}$ and $G_{d}$ are the generation number of the sire and dam respectively. The generation numbers of the base population sires and dams were set to zero. The base population was defined as foundation animals and their progeny (i.e. includes progeny born in the experiment which did not result from selection). Individual inbreeding coefficients were calculated according to the algorithm of Quaas (1976).

Direct and correlated cumulative selection differentials (CSD) were calculated within the control lines using the method of Newman et al. (1973) where an individual's selection differential, calculated as a deviation from the mean performance of its contemporary group, is added to the mean accumulated selection differential of all parents contributing progeny to the group. Only pre-weaning weight and weight gain traits were considered as males selected to be parents were managed separately post-weaning. Observations were either 'unadjusted' (except for age of calf for WW) or were 'adjusted' for fixed effects described in the above and the 'phenotypes' were taken as the residuals from the fixed effects analyses within control lines. Environmental trends were calculated by regressing line-year-environment solutions against year of birth for the control lines. Direct and correlated responses to selection were calculated by regressing EBV against generation number or year of birth. 
Table 1 Random components included in the analysis of the growth traits

\begin{tabular}{ll}
\hline Trait & Random component ${ }^{1}$ \\
\hline Birth weight & Direct; Sire x year; Maternal \\
Weaning weight & Direct; Sire x year; Maternal; Permanent; Direct-Maternal \\
Weight at 12 months & Direct; Sire x year; Maternal; Permanent; Direct-Maternal \\
Weight at 18 months & Direct; Sire x year; Maternal; Permanent \\
Post-weaning average daily gain & Direct; Sire x year; Maternal
\end{tabular}

\footnotetext{
${ }^{1}$ Direct genetic; Maternal genetic; Permanent maternal environmental; Covariance between direct-maternal genetic effects.
}

Realized heritability estimates for weights at birth and weaning were calculated within control lines by either the regression of an individual's breeding value estimate on its CSD (Falconer \& Mackay, 1996), where regressions were forced through the origin as suggested by Hill (1972) and reaffirmed by Baker et al. (1991), or by the ratio of total response to total cumulative selection differential after six generations. Responses were derived from the BLUP estimates, noting that these are subject to the REML estimate of heritability. The regression standard error seriously underestimates the standard error of the realized heritability estimate and the procedures described by Falconer \& Mackay (1996) were adopted to derive standard errors that accounts for random drift and measurement error.

\section{Results and Discussion}

The increase in generation number across years was very similar for the two lines, with the crossover being initiated after approximately two generations of selection had taken place in both lines, and the average generation number of calves born in 1997 was six (Figure 1), compared with a range of 1.8 to 6.3 generations of selection reported in the literature. In the pre-crossover phase, the average age of sires and dams at the time of birth of their progeny was 5.9 and 7.5 years, respectively. This was reduced to 4.4 and 6.5 years respectively in the post-crossover phase. These are similar to the generation interval of 5.1 reported by Mercadante et al. (2003) for a selection experiment with Nelore cattle in Brazil, but are in general higher than generation intervals reported in the literature of 2 to 4.3 years for sires and 4 to 6.6 years for dams (Baker et al., 1991; Koch et al., 1994; Parnell et al., 1997) and are primarily due to the late age at first mating of both sexes and longer retention of cows in the herd (Mercadante et al., 2003). The average level of inbreeding gradually increased with generation number and was slightly higher for the $\mathrm{S}$ lines reaching a level of 7.4\% compared with 5.7\% for the NS lines for calves born in 1997 (Figure 1). The rate of inbreeding across lines and environments was $0.2 \%$ /year or $1.2 \%$ /generation and is similar to estimates in the literature (0.07 to 0.3\%/year or 0.3 to 1.3\%/generation) (Baker et al., 1991; Koch et al., 1994; Parnell et al., 1997; Koch et al., 2004).

The effect of adjusting the traits for known factors influencing these traits did not materially affect the CSD. The CSD trends for both the $\mathrm{S}$ and NS lines for adjusted weaning weight plotted against generation number (Figure 2$)$ were relatively linear and greater $(\mathrm{P}<0.001)$ for the $\mathrm{S}$ line $(0.74$ s.d./generation; 0.10 s.d./year) compared to the NS line (0.51 s.d./generation; 0.07 s.d./year). Higher correlated selection differentials for weaning weight in beef cattle (where the primary selection trait was yearling weight) have been reported (0.14 to 0.22 s.d./year) (Mrode, 1988b; Baker et al., 1991). Mrode (1988b) attributed the inability to achieve maximum possible selection differentials to unsoundness, selection on colour, death before production of any offspring and failure to conceive as heifers.

Across traits and lines the direct and correlated responses were low (Table 2; Figures 3 and 4) and approximated $1 \%$ of the trait means per generation. The yearly genetic trends for weaning weight, the primary selection trait, were lower than correlated trends reported in the literature $(0.24$ and $0.22 \mathrm{~kg} / \mathrm{year}$ for the S and NS lines vs. 0.48 to $1.01 \mathrm{~kg} /$ year) (Baker et al., 1991; Arthur et al., 1997; Pereira et al., 2008), while the correlated yearly trends for yearling weight in the current study (Figure 4) were considerably lower 
than both direct and correlated literature estimates for Bos taurus and B. indicus cattle in the temperate and tropical regions (0.12 and $0.14 \mathrm{~kg} / \mathrm{year}$ for the S and NS lines vs. 1.2 to $2.8 \mathrm{~kg} / \mathrm{year}$ ) (Baker et al., 1991; Koch et al., 1994; Parnell et al., 1997; Razook et al., 1998; Mercadante et al., 2003; Koch et al., 2004; Pereira et al., 2008). The correlated selection response of BW in the NS line was twice that of calves in the S line and both estimates were within the range of literature estimates $(0.04$ and $0.07 \mathrm{~kg} /$ year for the S and NS lines vs. -0.06 to $0.25 \mathrm{~kg}$ /year) (Baker et al., 1991; MacNeil et al., 1992; Arthur et al., 1997; Pereira et al., 2008). The direct and correlated selection responses reflect the low applied selection pressure. A possible reason for the low selection differential could be due to selection being carried out on observed values pre-1988. However, no consistent differences were found between CSD calculated with or without adjustments for fixed effects, suggesting emphasis was placed on secondary criteria.

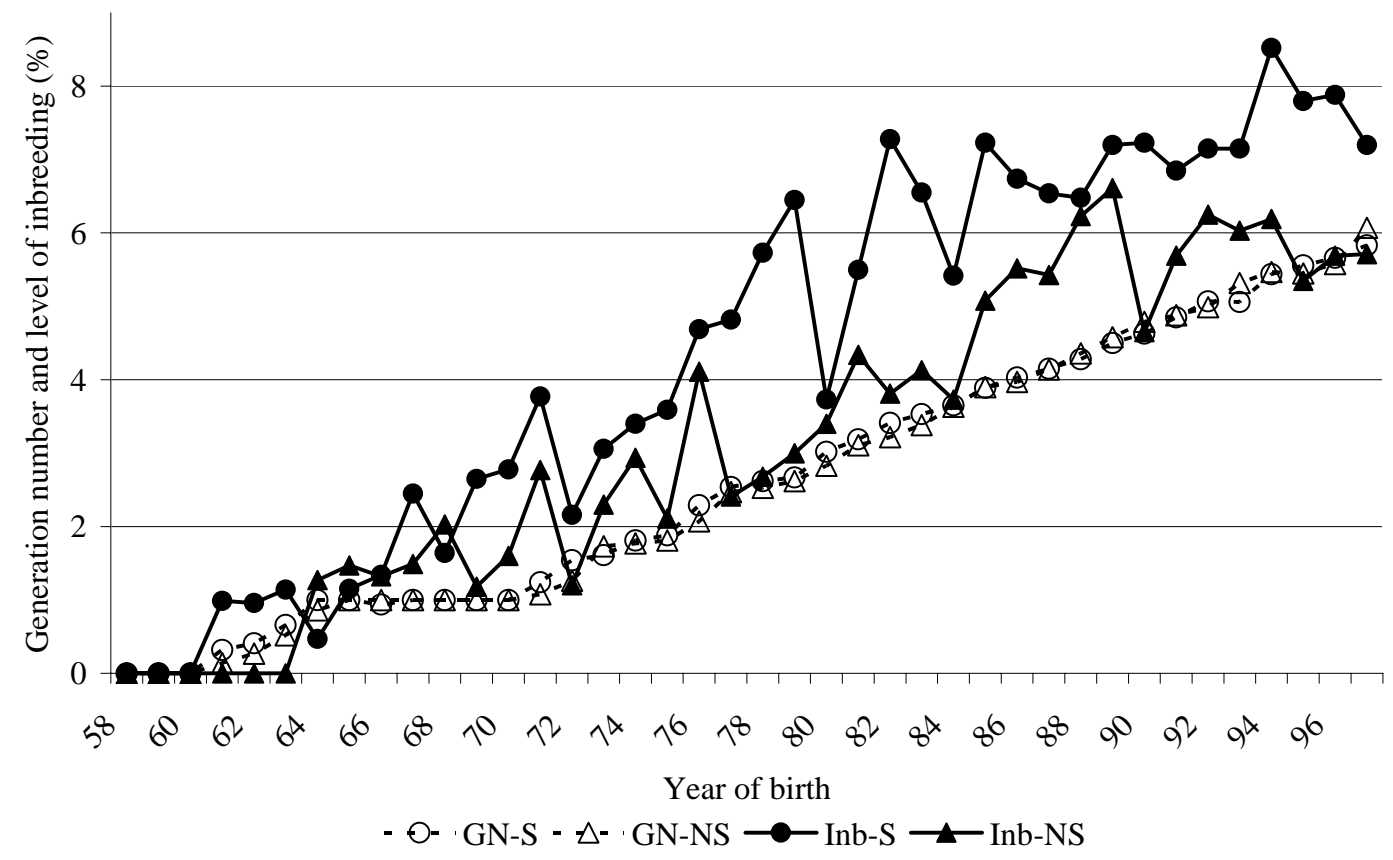

Figure 1 Generation number (GN) and level of inbreeding (Inb) (\%) against year of birth for the supplemented (S) and non-supplemented (NS) lines.

Table 2 Genetic trends (kg/per generation) for calf growth traits for the supplemented (S) and nonsupplemented (NS) lines ${ }^{1}$

\begin{tabular}{|c|c|c|c|c|}
\hline \multirow[b]{2}{*}{ Trait } & \multicolumn{2}{|c|}{ Direct genetic } & \multicolumn{2}{|c|}{ Maternal genetic } \\
\hline & $\mathrm{S}$ & NS & $\mathrm{S}$ & NS \\
\hline Birth weight & $0.24 \pm 0.018^{* *}$ & $0.46 \pm 0.018^{* *}$ & $-0.03 \pm 0.008^{* *}$ & $0.16 \pm 0.009 * *$ \\
\hline Weaning weight & $1.53 \pm 0.036^{* *}$ & $1.39 \pm 0.037^{* *}$ & $-0.04 \pm 0.045^{\mathrm{ns}}$ & $0.81 \pm 0.047^{* *}$ \\
\hline Weight at 12 months & $0.78 \pm 0.029^{* *}$ & $0.87 \pm 0.031^{* *}$ & $-0.29 \pm 0.049 * *$ & $0.97 \pm 0.051^{* *}$ \\
\hline Weight at 18 months & 2.10 & $45^{* *}$ & $-0.11 \pm 0.043^{*}$ & $0.68 \pm 0.045^{* *}$ \\
\hline
\end{tabular}

\footnotetext{
${ }^{1}$ Regression coefficients ( \pm standard errors), either within line where significantly different $(\mathrm{P}<0.10)$, or pooled across line;

${ }^{\text {ns }}$ - non-significant; ${ }^{\dagger}$ - $\mathrm{P}<0.10$; * $\mathrm{P}<0.05$; ** - P $<0.01$ : probabilities of regression being different from zero.
}

The maternal genetic trends displayed marked deviation after approximately two generations of selection (Figures 3 and 4), coinciding with the crossover, and for the S line either showed no trend or were negative, while those for the NS line were all positive ( $<<0.01$ ), ranging from $30 \%$ (BW \& W18) to $110 \%$ 
(W12) of the direct estimate (Table 2). Some studies have shown that maternal effects positively and significantly contributed to correlated responses in weaning and yearling weights (Herd, 1990; MacNeil et al., 1992; Koch et al., 1994), while other reports have shown marginal contribution (Carter et al., 1990; Morris et al., 1992). Arthur et al. (1997) noted that the differences may partly be due to the absolute importance of maternal ability on expression of growth and partly due to the magnitude and sign of genetic correlations between direct and maternal effects. Despite the differential response of maternal effects between the lines, there were no indications of a line $\mathrm{x}$ environment interaction for maternal effects (Beffa et al., 2009b).

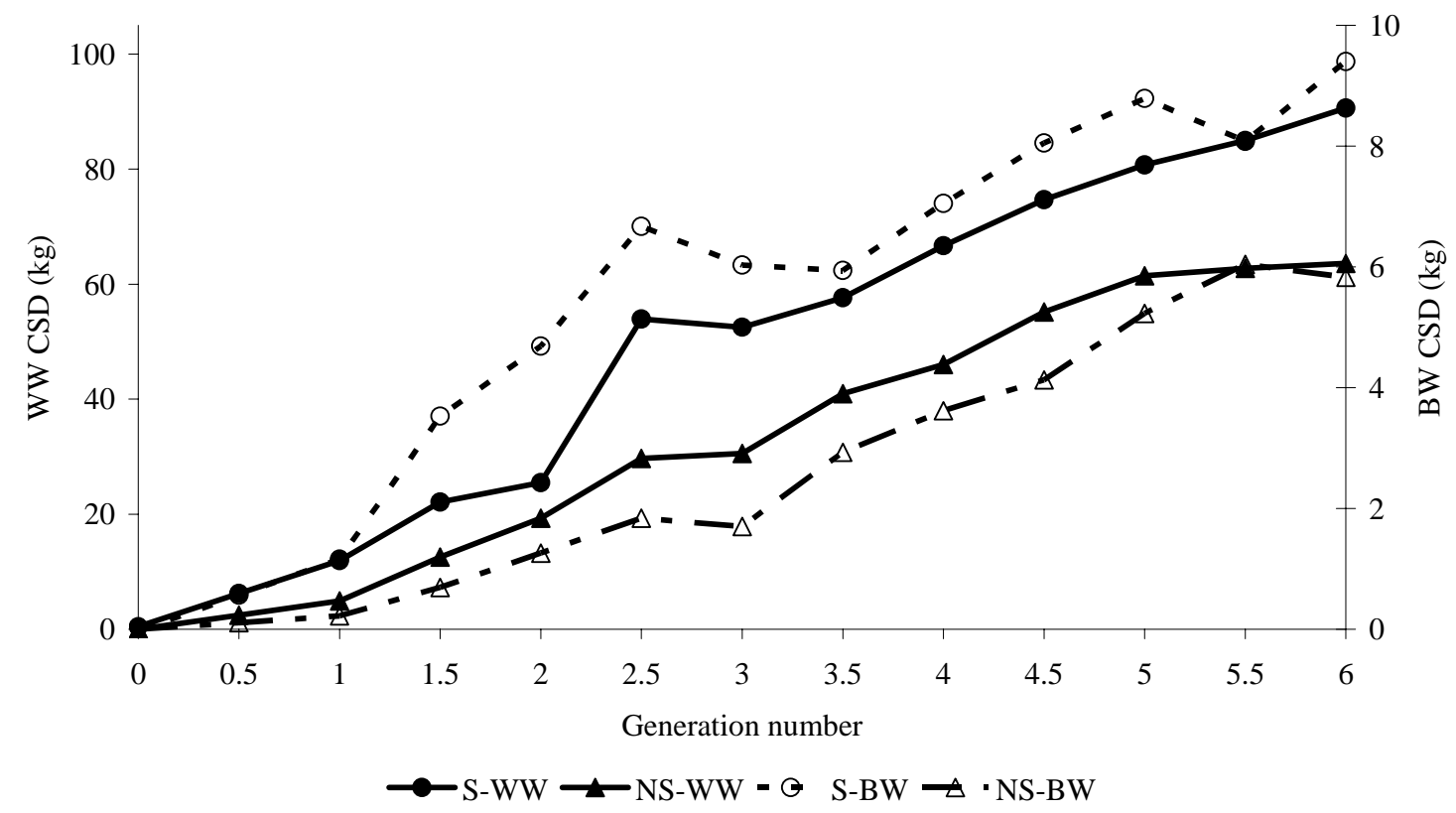

Figure 2 Weaning weight (WW) and birth weight (BW) cumulative selection differentials (CSD) for the supplemented (S) and non-supplemented (NS) lines.

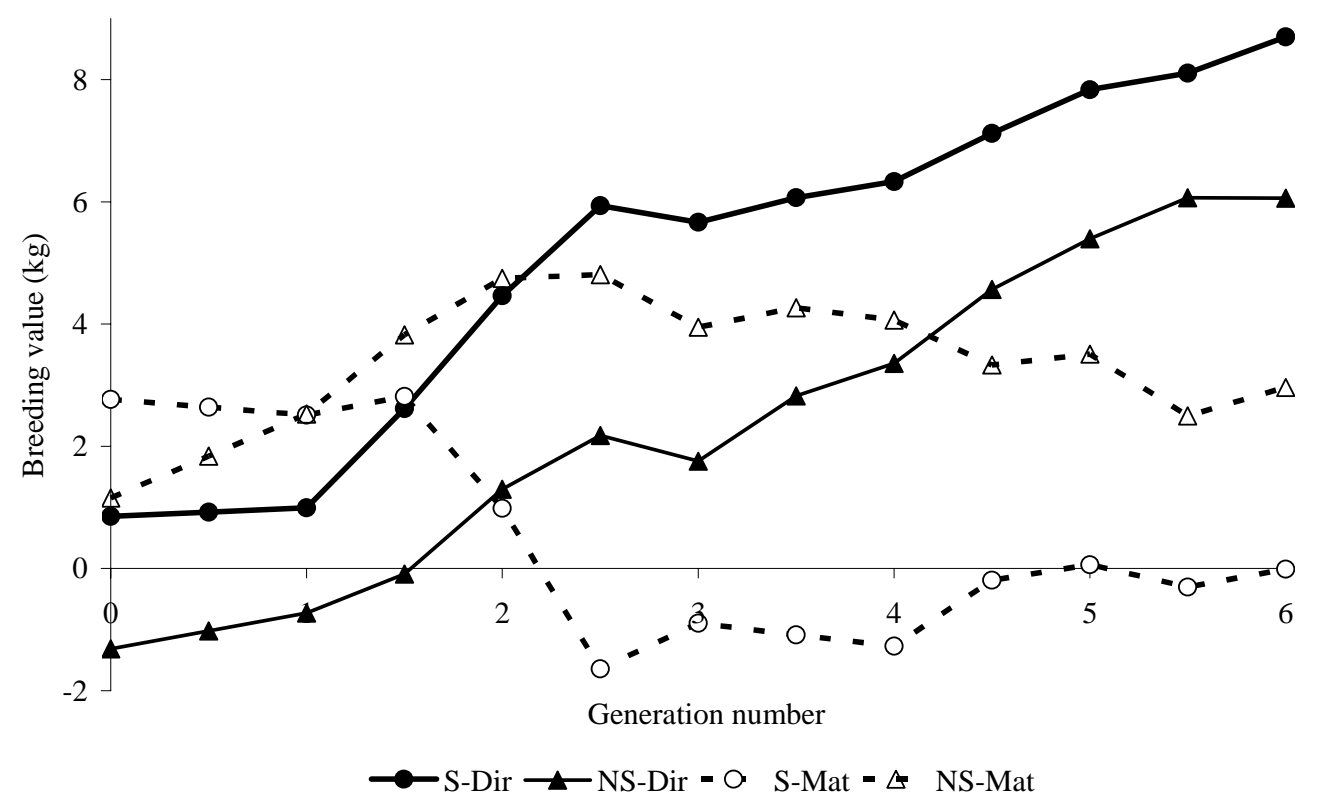

Figure 3 Weaning weight direct (Dir) and maternal (Mat) genetic trends for the supplemented (S) and nonsupplemented (NS) lines. 
The estimates of realized heritability by regression and by the ratio of total response to the cumulative selection differential after six generations were similar to each other and generally lower than the REML estimates (Table 3). The lower realized heritabilities for the weight gain traits are consistent with findings in other selection studies (Baker \& Morris, 1984). Thompson \& Juga (1989) showed that the method of Newman et al. (1973) is biased downwards as a result of a reduction in variance due to linkage disequilibrium (Bulmer, 1971) and proposed a recursive method to estimate realized heritabilities. Reporting on a selection experiment with sheep, Johnson et al. (1995) found lowest realized heritabilities estimated by

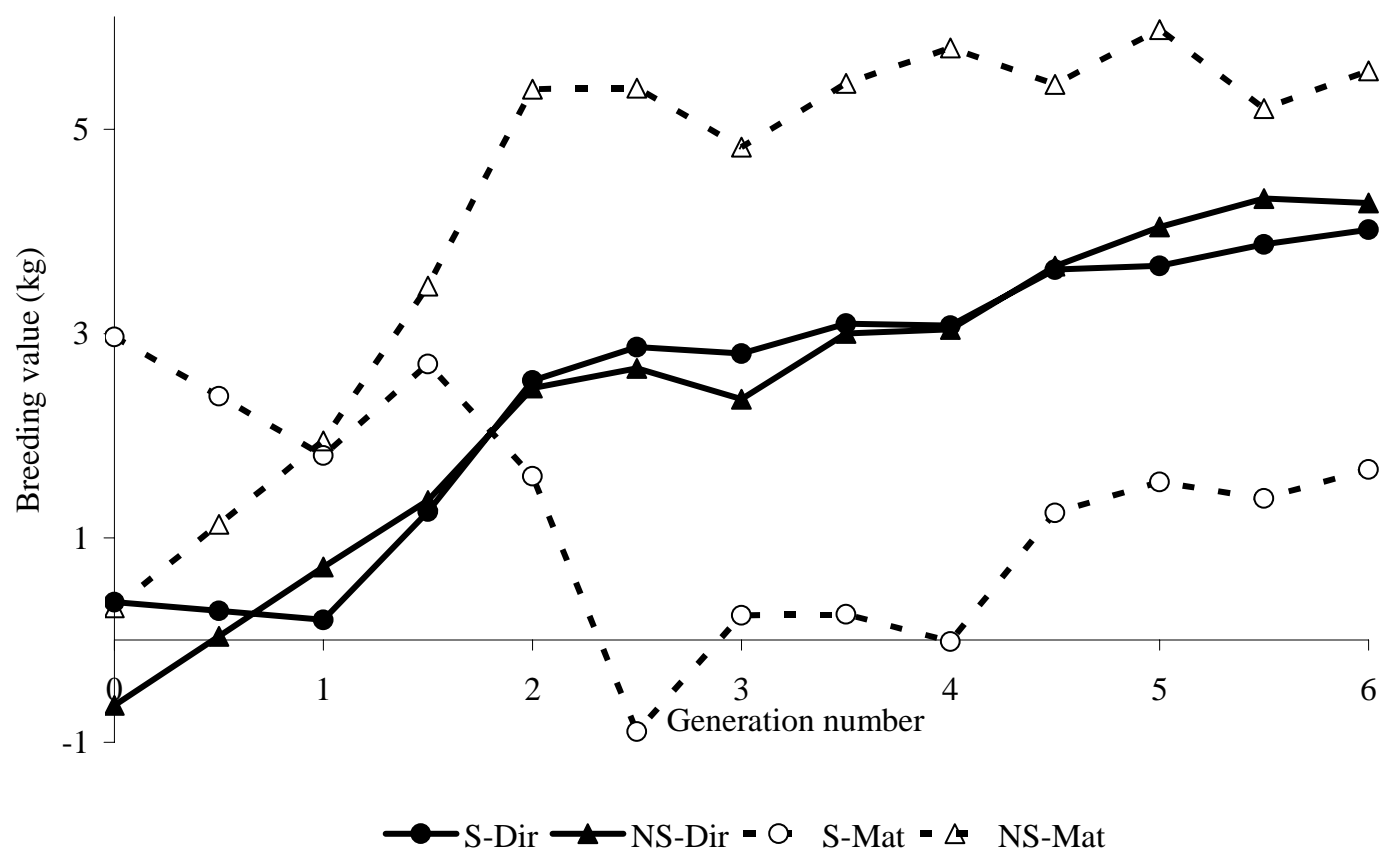

Figure 4 Yearling weight direct (Dir) and maternal (Mat) genetic trends for the supplemented (S) and nonsupplemented (NS) lines.

the method of Newman et al. (1973) followed by those estimated using the method of Thompson \& Juga (1989) which were similar to, but still lower than, the REML estimates. The low selection response for weaning weight was due to the low REML heritability estimate which was influenced by the presence of sire $\mathrm{x}$ year interaction (Beffa et al., 2009b). In theory, REML techniques using an animal model and complete relationship matrix yield unbiased estimated of base population parameters (Johnson et al., 1995). However, Meyer \& Hill (1991) found that REML analyses did not account for a decrease in genetic variance in the analyses of 23 generations of selection in mice.

Table 3 Within line direct and correlated realized heritabilities ${ }^{1}$ ( \pm s.e.) compared with the REML heritability estimates

\begin{tabular}{lccccc}
\hline Trait & \multicolumn{2}{c}{ Supplemented } & \multicolumn{2}{c}{ Non-supplemented } & REML \\
\hline Birth weight & $0.24(0.00)$ & $0.17(0.13)$ & $0.35(0.00)$ & $0.39(0.18)$ & $0.39(0.04)$ \\
Weaning weight & $0.09(0.00)$ & $0.10(0.04)$ & $0.08(0.00)$ & $0.10(0.05)$ & $0.13(0.03)$ \\
\hline
\end{tabular}




\section{Conclusions}

The generation interval and increase in inbreeding were consistent with other long-term selection experiments with cattle. Direct and cumulative selection differentials were low but positive, indicating considerable attention was given to secondary characters. Direct and correlated responses were correspondingly low and in the region of $1 \%$ /generation. While maternal responses were generally slightly negative for the S line, the corresponding values for the NS line were all positive, and in one instance, greater than the direct response. Realized heritabilities were also generally low, and particularly in the case of weaning weight, the trait under selection, was influenced by the low REML heritability. These results concur with general findings of effective direct and correlated responses of weight traits to individual selection.

\section{Acknowledgements}

The algorithm to calculate cumulative selection differentials was kindly provided by D. Garrick. Funding for this study was provided by: John Wakeford Scholarship Trust; Afrikaner Cattle Society of South Africa; International Livestock Research Institute; National Research Foundation and Livestock Identification Trust. This work was carried out at Matopos Research Station, Department of Research and Specialist Services, Zimbabwe.

\section{References}

Arthur, P.F., Parnell, P.F. \& Richardson, E.C., 1997. Correlated responses in calf body weight and size for yearling growth rate in Angus cattle. Livest. Prod. Sci. 49, 305-312.

Baker, R.L. \& Morris, C.A., 1984. A review of correlated responses to weight selection in beef cattle under different management and climate conditions. Proc. $2^{\text {nd }}$ World Congr. Sheep Beef Cattle Breed. 236-251.

Baker, R.L., Morris, C.A., Johnson, D.L., Hunter, J.C. \& Hickey, S.M., 1991. Results of selection for yearling or 18-month weight in Angus and Hereford cattle. Livest. Prod. Sci. 29, 277-296.

Beffa, L.M., Van Wyk, J.B. \& Erasmus, G.J., 2009a. Long-term selection experiment with Afrikaner cattle. 1. Environmental factors affecting calf growth. S. Afr. J. Anim. Sci. 39, 89-97.

Beffa, L.M., Van Wyk, J.B. \& Erasmus, G.J., 2009b. Long-term selection experiment with Afrikaner cattle. 2. Genetic parameters and genotype $x$ environment interaction for calf growth traits. S. Afr. J. Anim. Sci. 39, 98-105.

Brinks, J.S., Clark, R.T. \& Rice, F.J., 1961. Estimation of genetic trend in beef cattle. J. Anim. Sci. 20, 903 (Abstract).

Bulmer, M.G., 1971. The effect of selection on genetic variability. Amer. Nat. 105, 201-211.

Carter, A.H., Morris, C.A., Baker, R.L., Bennett, G.L., Johnson, D.L., Hunter, J.C. \& Hickey, S.M., 1990. Long-term selection for yearling or post weaning gain in Angus cattle. N. Z. J. Agric. Res. 33, 49-61.

Pereira, M.C., Mercadante, M.E.Z., Razook, A.G., Figueiredo, L.A. \& Albuquerque, L.G., 2008. Results of 23 years of selection for post-weaning weight in a Caracu beef herd. S. Afr. J. Anim. Sci. 38, 136-144.

Falconer, D.S., 1977. Some results of the Edinburgh selection experiments with mice. Proc. Int. Conf. Quant. Genet., Ames, Iowa, August 16-21, 1976, 101-115.

Falconer, D.S. \& MacKay, T.F.C., 1996. Introduction to Quantitative Genetics. $4^{\text {rd }}$ ed., Longman, Essex, UK.

Frisch, J.E., 1981. Changes occurring in cattle as consequence of selection for growth in a stressful environment. J. Agric. Sci., Camb. 96, 23-28.

Gilmour, A.R., Gogel, B.J., Cullis, B.R., Welham, S.J. \& Thompson, R., 2002. ASREML User Guide Release 1.0. VSN International Ltd, Hemel Hempstead, HP11es, UK.

Herd, R.M., 1990. The direct and maternal components of the response to divergent selection for yearling growth rate in Angus cattle. Anim. Prod. 45, 42-44.

Hill, W.G., 1972. Estimation of realized heritabilities from selection experiments. 2. Selection in one direction. Biometrics 27, 293-311.

Johnson, D.L., Hight, G.K., Dobbie, J.L., Jones, K.R. \& Wrigglesworth, A.L., 1995. Single trait selection for yearling fleece weight or liveweight in Romney sheep - direct responses. N. Z. J. Agric. Res. 38, 115-122. 
Koch, R.M., Cundiff, L.V. \& Gregory, K.E., 1994. Cumulative selection and genetic change for weaning or yearling weight or for yearling weight plus muscle score in Hereford cattle. J. Anim. Sci. 72, 864-885.

Koch, R.M., Cundiff, L.V., Gregory, K.E. \& Van Vleck, L.D., 2004. Genetic response to selection for weaning weight or yearling weight or yearling weight and muscle score in Hereford cattle: Efficiency of gain, growth, and carcass characteristics. J. Anim. Sci. 82, 668-682.

MacNeil, M.D., Urick, J.J., Newman, S. \& Knapp, B.W., 1992. Selection for post weaning growth in inbred Hereford cattle: The Fort Keogh, Montana Line 1 example. J. Anim. Sci. 70, 723-733.

Mercadante, M.E.Z., Packer, I.U., Razook, A.G., Cyrillo, J.N.S.G. \& Figueiredo, L.A., 2003. Direct and correlated responses to selection for yearling weight on reproductive performance of Nelore cows. J. Anim. Sci. 2003, 376-384.

Meyer, K. \& Hill, W.G., 1991. Mixed model analysis of a selection experiment for food intake in mice. Genet. Res. 57, 71-81.

Morris, C.A., Baker, R.L. \& Hunter, J.C., 1992. Correlated responses to selection for yearling or 18-month weight in Angus and Hereford cattle. Livest. Prod. Sci. 30, 33-52.

Mrode, R.A., 1988a. Selection experiments in beef cattle. Part 1: A review of design and analysis. Anim. Breed. Abstr. 56, 155-167.

Mrode, R.A., 1988b. Selection experiments in beef cattle. Part 2: A review of responses and correlated responses. Anim. Breed. Abstr. 56, 155-167.

Newman, J.A., Rahnefeld, G.W. \& Fredeen, H.T., 1973. Selection intensity and response to selection for yearling weight in beef cattle. Can. J. Anim. Sci. 53, 1-12.

Parnell, P.F., Arthur, P.F. \& Barlow, R., 1997. Direct response to divergent selection for yearling growth rate in Angus cattle. Livest. Prod. Sci. 49, 297-307.

Quaas, R.L., 1976. Computing the diagonal elements and inverse of a large numerator relationship matrix. Biometrics 32, 949-953.

Razook, A.G., Figueiredo, L.A., Bonilha Neto, L.M., Trovo, J.B.F., Packer, L.U., Pacola, L.J., Cyrillo, J.N.S.G., Ruggieri, A.C. \& Mercadante, M.E.Z., 1998. Selection for yearling weight in Nelore and Guzera Zebu breeds: Selection applied and response in 15 years of progeny. Proc. $6^{\text {th }}$ World Congr. Genet. Appl. Livest. Prod. 23, 133-136.

Thompson, R. \& Juga, J., 1989. Cumulative selection differentials and realized heritabilities. Anim. Prod. 49, 203-208.

Van Vleck, L.D., 1977. Theoretical and actual genetic progress in dairy cattle. Proc. Int. Conf. Quant. Genet., Ames, Iowa, August 16-21, 1976, 543-567. 